\title{
A Study to Assess the Effectiveness of Video-assisted Teaching on the Knowledge of Parents Regarding the Effects of Smartphone Overuse on the Growth and Development of Pre-schoolers in Selected Schools of Navi Mumbai
}

\author{
Jays George, Mankumari Mistry \\ Department of Child Health Nursing, DY Patil College of Nursing, Navi Mumbai, Maharashtra, India
}

\section{Abstract}

Background: Smartphone overuse is a major concern for children which lead to hampering of their social, cognitive, physical, and mental development.

Aim: This study aimed to assess the effectiveness of video-assisted teaching on the knowledge of parents regarding the effects of smartphone overuse on the growth and development of pre-schoolers in selected schools of Navi Mumbai.

Subjects and Methods: The researcher adopted a quantitative approach with one-group pretest-posttest design. Fifty parents were selected by simple convenient sampling method. Pretest video-assisted teaching program on Smartphone overuse was given by investigator, after that, post-test was done after 1 week with the help of structured questionnaire. The collected data were analyzed based on the above-mentioned objective using the descriptive and inferential statistics.

Results: The study identified that the video-assisted teaching program was effective after conducting knowledge regarding health hazards of smartphone overuse.

Conclusion: From the results of the study, it is concluded that video-assisted teaching was effective in promoting knowledge regarding health hazards of Smartphone overuse.

Keywords: Health hazards, nursing, pre-schoolers, smartphone

\section{INTRODUCTION}

Mobile phone addiction/abuse/misuse is one of the forms of compulsive use of "a mobile phone" by people across the world. A new kind of health disorder in this category, "smartphone's addiction/abuse/misuse" is now challenging health policy-makers globally to think on this rapidly emerging issue. Indian adolescents and adults are also affected by this high smartphone engagement.

\begin{tabular}{|l|}
\hline \multicolumn{1}{|c|}{ Access this article online } \\
\hline Website: http://innovationalpublishers.com/Journal/ijnmi \\
\hline ISSN No: $2656-4656$ \\
DOI: $10.31690 /$ ijnmi/48 \\
\hline
\end{tabular}

A Smartphone, or smartphone, is a term for distinguishing mobile phones with advanced features from basic feature phones. The term "Smartphone" first appeared in 1997, when Ericsson described its GS88 "Penelope" concept as a smartphone. ${ }^{[1]}$ This term was basically introduced in the market for a new class of mobile phones that provides integrated services from communication, computing, and mobile sectors such as voice communication, messaging, personal information management applications, and wireless communication capability. ${ }^{[2]}$

The age group of 25-34 years is found to have the highest Smartphone usage rate of $62 \% .50 \%$ of Android Smartphones and $43 \%$ of Apple iPhone users are younger than 34 years. ${ }^{[3]}$ $53 \%$ of Smartphone users are male and $47 \%$ are female. ${ }^{[4]}$ 
Indian teens are currently driving the Smartphones' market in India. The age groups of 16-18 years using Smartphones have shown a rapid rise from $5 \%$ in $2012-25 \%$ in early $2014 . .^{[3,4]}$ Recently, in 2013, there were around "51 million" Smartphone users in Urban India and the rate of rise from year 2012 was $90 \%{ }^{[3,4]}$ Significant increase in Smartphone use and their capabilities allow people to access the Internet, communicate, and entertain themselves anywhere and anytime.

In 2015, WEHAVEKIDS published an inspirational article on "Positive and Negative Impacts of Electronic Devices on Children" revealed that electronic devices can be useful but also have a negative impact if they are overused. ${ }^{[5]}$ Addiction of smartphones in the pre-school children is creating a more negative effect than the positive ones. The excess overuse is resulting in hindrance in physical, emotional, social, and cognitive development of the children. Hence, this study was aimed to assess the effectiveness of video-assisted teaching on the knowledge of parents regarding the effects of smartphone overuse on the growth and development of pre-schoolers in selected schools of Navi Mumbai.

\section{Subjects and Methods}

The study was conducted in Rainbow Preschool International, Sector-12A, Koparkhairane, Navi Mumbai. The study population consisted of 50 parents of pre-schoolers from December 12, 2017, to December 18, 2017. The parents were included in the study if they were willing to participate, able to comprehend English, and aged between 18 and 48 years. The parents who were illiterate, blind, participated in similar studies earlier, and not willing to participate in the study were excluded from enrollment.

\section{Data collection}

A semi-structured knowledge questionnaire was developed to collect the data. The questionnaire consisted of four sections. Section I consisted of 12 items for obtaining information about the selected sociodemographic data such as age, sex, qualification, residence, type of family, age of child, and if they have attended any previous workshops and seminars on the same research topic regarding effects of Smartphone overuse in children. The items related to demographic characteristics were not scored. Section II consisted of checklist with yes or no questions for obtaining information about the parents' knowledge regarding normal growth and developmental milestones of their pre-school child, which includes 25 items based on the selected aspects of normal growth and development of pre-school stage. Sections III and IV consisted of knowledge questionnaire regarding effects of Smartphone overuse and its management which includes 21 items. It is divided into two sections. Section III includes 10 questions regarding the effects of Smartphone overuse in kids and the Section IV consists of 11 questions related to management of kids' Smartphone overuse. Each question had four options and the participant had to put a tick mark against each option.
A total of 21 questions were scored against parents' response. The knowledge level was defined on the basis of score category: excellent (17-21), very good (13-16), good (10-12), average (6-9), and poor (0-5).

\section{Validity and reliability of tool}

The content was validated by 10 experts from various fields. The experts for tool validation included a doctor, a statistician, and 8 nursing faculties. The suggestions put forth by experts included points such as arrange in sequence, prepare checklist for normal growth and developmental milestones of pre-schoolers, and arrange income status and educational qualification according to the Kuppuswamy scale. The tool was modified by incorporating the above comments. In this study, reliability of tool was tested on five samples selected according to the pre-determined criteria using test-retest method and the reliability was tested using Karl Pearson's correlation coefficient. The obtained reliability value was $r=0.90$ which is considered to be reliable and adequate.

\section{Intervention}

Video-assisted teaching was developed as intervention program to teach parents on normal growth and development of pre-schoolers, effects of smartphone overuse on the growth and development of pre-schoolers, and management of kids' smartphone overuse. Content of the video-assisted teaching was prepared by reviewing of literature, articles consultation, and discussion with the nursing experts, parents, and personal experience. Content includes normal growth and developmental milestones of pre-school stage, effects of Smartphone overuse in kids, and management of kids smartphone overuse. Video-assisted teaching was given for a period of 20 min regarding effects of smartphone overuse on the growth and development of pre-schoolers. The video-assisted teaching was given to the whole group in three sessions. Fifty samples were given pre-test and videoassisted teaching. The post-test was carried out individually after 7 days for the same sample. The same was repeated till the sample size of 50 was achieved.

\section{Statistical analysis}

Data were presented as frequency, percentages, mean, and standard deviation. Paired $t$-test was used to compare pre- and post-knowledge scores. Chi-square test was used to find the association between knowledge score and demographic variables.

\section{Ethical consideration}

The study was approved by the institutional ethical review committee. Detailed explanation was given to each study participant about the purpose of the study, and informed consent was obtained from the parents. The confidentiality of the responses was assured.

\section{RESULTS}

Table 1 shows demographic variables of the study participants. $68 \%$ of samples aged 29-38 years. Male-to-female ratio was 
$1.5: 1.62 \%$ of the parents had only one child. Major percentage of the samples resided in urban area, i.e., 30 (60\%), whereas only $16(32 \%)$ belonged to rural area. Majority of $22(44 \%)$ of the sample family income were above Rs. 30001 and minimum of $2(4 \%)$ were $<10000.76 \%$ of parents were graduate. The most parents were from private sector with the percentage of $41(82 \%)$, whereas $7(14 \%)$ were from government sector, and occupation from daily wages and unemployed shared the same percentage of $1(2 \%)$. The highest percentage of samples came from a nuclear family with a percentage of $29(58 \%)$. The highest percentage of weight was seen between 11 and $13 \mathrm{~kg}$

Table 1: Demographic variables $(n=50)$

\begin{tabular}{|c|c|}
\hline Particulars & $n(\%)$ \\
\hline \multicolumn{2}{|l|}{ Age } \\
\hline $18-28$ years & $13(26)$ \\
\hline 29-38 years & $34(68)$ \\
\hline 39-48 years & $3(6)$ \\
\hline \multicolumn{2}{|l|}{ Sex } \\
\hline Male & $20(40)$ \\
\hline Female & $30(60)$ \\
\hline \multicolumn{2}{|l|}{ Number of children } \\
\hline 1 & $31(62)$ \\
\hline 2 & $18(36)$ \\
\hline$\geq 3$ & $1(2)$ \\
\hline Residence & $16(32)$ \\
\hline \multicolumn{2}{|l|}{ Rural } \\
\hline Urban & $30(60)$ \\
\hline Rural slum & $3(6)$ \\
\hline Urban slum & $1(2)$ \\
\hline \multicolumn{2}{|l|}{ Monthly income } \\
\hline$<10000$ & $2(4)$ \\
\hline $10001-20000$ & $9(18)$ \\
\hline $20001-30000$ & $17(34)$ \\
\hline$>30001$ & $22(44)$ \\
\hline \multicolumn{2}{|l|}{ Parental education } \\
\hline Illiterate & $0(0)$ \\
\hline Primary & $0(0)$ \\
\hline Secondary & $2(4)$ \\
\hline Higher secondary & $10(20)$ \\
\hline Graduate and above & $38(76)$ \\
\hline \multicolumn{2}{|l|}{ Occupation } \\
\hline Government employee & $7(14)$ \\
\hline Private & $41(82)$ \\
\hline Daily wages & $1(2)$ \\
\hline Unemployed & $1(2)$ \\
\hline \multicolumn{2}{|l|}{ Type of family } \\
\hline Nuclear family & $29(58)$ \\
\hline Joint family & $21(42)$ \\
\hline \multicolumn{2}{|l|}{ Children age } \\
\hline 3 years -4 years & $34(68)$ \\
\hline 4 years and 1 month- 5 years & $10(20)$ \\
\hline 5 years and 1 month- 6 years & $6(12)$ \\
\hline \multicolumn{2}{|l|}{ Children weight } \\
\hline $11-13$ & $26(52)$ \\
\hline $13.1-15$ & $12(24)$ \\
\hline $15.1-17$ & $12(24)$ \\
\hline \multicolumn{2}{|l|}{ Child height } \\
\hline $85-95$ & $28(56)$ \\
\hline $96-105$ & $15(30)$ \\
\hline$>105$ & $7(14)$ \\
\hline \multicolumn{2}{|l|}{ Playthings } \\
\hline Toys & $13(26)$ \\
\hline Video games & $3(6)$ \\
\hline Smartphones & $30(60)$ \\
\hline Outdoor games & $4(8)$ \\
\hline
\end{tabular}

with $26(52 \%)$, and the percentage of weight between 13.1 and $15 \mathrm{~kg}$ and $15.1-17 \mathrm{~kg}$ were same $12(24 \%)$, respectively. With regard to weight of the child, majority of children weight were seen below $13 \mathrm{~kg}$. The highest percentage of height were seen between 85 and $95 \mathrm{~cm}$ with $28(56 \%)$ and the percentage of height between 96 and $105 \mathrm{~cm}$ were only 15 (30\%). It was seen that mostly used plaything was Smartphone with a percentage of $30(60 \%)$ and the rest $13(26 \%)$ of children only were using toys as plaything. The least percentage of children like to play with video games, and outdoor games were only $3(6 \%)$ and $4(8 \%)$, respectively.

\section{Knowledge of parents regarding normal milestones of} their own pre-school child

Majority of the parents who said yes (79\%) were cognizant regarding their child's normal growth and developmental milestones, whereas an insignificant proportion of parents said no $(21 \%)$, revealing that they were uninformed regarding normal developmental milestones of their pre-school child [Figure 1].

\section{Knowledge regarding effects of Smartphone overuse on} the growth and development of preschoolers

Table 2 shows that majority $(23,46 \%)$ of the parents had an average knowledge of score (6-9) during pre-test, whereas in post-test, knowledge score of the parents improved, with a majority of $25(50 \%)$ having very good knowledge.

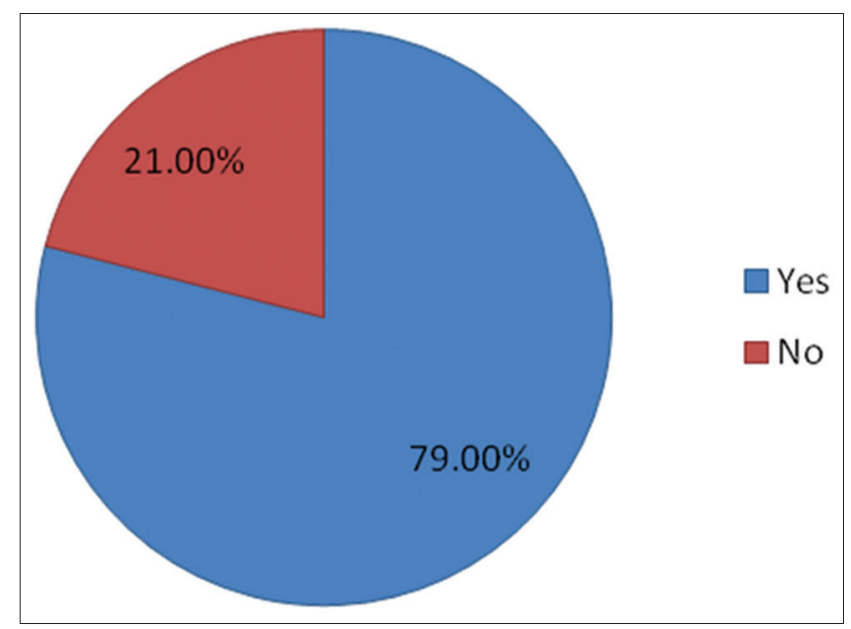

Figure 1: Knowledge regarding normal milestones

Table 2: Level of knowledge obtained by parents regarding effects of smartphone overuse on the growth and development of preschoolers $(n=50)$

\begin{tabular}{lccccc}
\hline Grade & \multicolumn{2}{c}{ Pre-test } & & \multicolumn{2}{c}{ Post-test } \\
\cline { 2 - 3 } \cline { 5 - 6 } & Score & Percentage & & Score & Percentage \\
\hline Poor (0-5) & 5 & 10 & & 0 & 0 \\
Average (6-9) & 23 & 46 & & 0 & 0 \\
Good (10-12) & 14 & 28 & & 7 & 14 \\
Very good (13-16) & 8 & 8 & & 25 & 50 \\
Excellent (17-21) & 0 & 0 & & 18 & 36 \\
\hline
\end{tabular}


Video-assisted teaching was effecting in increasing knowledge regarding the effects of Smartphone overuse on the growth and development of preschoolers

Paired $t$-test showed that there was a significant increase in the mean score of the pretest knowledge from 8.34 to post-test knowledge score $15.36(P<0.05)$ [Table 3].

\section{Age was associated with knowledge score}

Age of child was significantly associated with the knowledge of the sample as $P=10.41$ which is greater than tabulated value at the level of significance $(P=0.05)$; therefore, the null hypothesis $\mathrm{HO}_{2}$ was rejected and alternative hypothesis $\mathrm{H}_{2}$ was accepted which stated that there was a significant association between sociodemographic variables and the level of knowledge regarding the effects of Smartphone overuse on the growth and development of preschoolers.

\section{Discussion}

Individuals who are addicted to Smartphones are seeking easier interactions than those they experience in the real world. Smartphones may have different impacts on their social lives than other individuals. They may not use Smartphones to increase their interactions and social engagement.

Previous studies have demonstrated varied negative outcomes of media addictions. Media addiction generates psychological problems such as feeling worthless when not online or feeling lonely and depressed. However, the research has rarely addressed the influence of smartphone addiction on individual's social behaviors such as social engagement. Children's social engagement is essential for their psychological and physical wellbeing as well as the growth of democratic society. ${ }^{[6]}$ Furthermore, while previous studies found that individuals, in general (instead of smartphone addicts), use new media to generate offline social engagement (e.g., volunteering, promoting social issues, rallying for political parties, or working on community projects) by gathering useful knowledge, information, or opportunities for the engagement, ${ }^{[7]}$ these results may not apply to smartphone addicts. Because smartphone addiction is closely related to a desire to escape from offline social interactions, ${ }^{[8]}$ smartphone addicts may not take advantage of smartphones to build offline social engagement; they may not participate in social activities, which require more active interactions and confrontation with others. As such, research is necessary to reveal how different population's use of smartphones might have different social outcomes in comparison to previous findings.

Our study observed that only $36 \%$ of parents had good to excellent knowledge before the implementation of

\section{Table 3: Comparison of mean score of pre-test and} post-test $(n=50)$

\begin{tabular}{lccccc}
\hline Test & Mean \pm SD & $\begin{array}{c}\text { Calculated } \\
\boldsymbol{t} \text {-value }\end{array}$ & $\begin{array}{c}\text { Degree of } \\
\text { freedom }\end{array}$ & $\begin{array}{c}\text { Table } \\
\text { value }\end{array}$ & $\begin{array}{c}\boldsymbol{P} \text { value } \\
\text { (Significant) }\end{array}$ \\
\hline Pre-test & $8.34 \pm 3.52$ & 10.111 & 49 & 2.02 & $P<0.05$ \\
Post-test & $15.36 \pm 2.45$ & & & & \\
\hline
\end{tabular}

video-assisted teaching while the intervention resulted in $100 \%$ knowledge gain with good to excellent score.

Many of the programs designed to promote positive parenting in early childhood have been evaluated in carefully controlled trials, resulting in a substantial number of evidence-based parenting interventions targeting children in the age range of 0-5 years. For example, in a recent review, Child Trends identified 32 parenting interventions for young children as evidencebased, based on findings from controlled research trials of positive impact in at least one domain of child functioning (e.g., physical health, cognitive development, externalizing behavior, social skills, and mental health) or parent functioning (e.g., substance use, child maltreatment, parent-child relationship quality, and parenting skills). ${ }^{[9]}$

In designing future intervention innovations and research designs, it becomes important to anticipate how emerging trends in technology might affect program accessibility and impact. For example, the increasing multipurpose capacity of smartphones may be changing patterns of Internet use in ways that will affect web-based intervention design. Parents may increasingly prefer to access parenting information or support through their phones, potentially decreasing the digital divide, but requiring a reworking of the platforms used for intervention delivery. In general, future research will need to monitor the accessibility and acceptability of technology use for various populations in an ongoing manner, to optimally navigate this rapidly developing landscape. ${ }^{[10]}$

\section{ConcLusion}

Video-assisted teaching programs can be used to increase knowledge and awareness about the Smartphone overuse in the children. Further studies with larger sample size and new intervention techniques are required.

\section{REFERENCES}

1. Kim H. Exercise rehabilitation for smartphone addiction. J Exerc Rehabil 2013;9:500-5.

2. Sarwar M, Soomro TR. Impact of smartphone's on society. Eur J Sci Res 2013;98:216-26.

3. Katz JE, Akhus M. Perpetual Contact: Mobile Communication, Private Talk, Public performance United Kingdom: Cambridge University Press; 2002.

4. Smartphone Users around the World Statistics and Facts [Infographic]. Available from: http://www.go-gulf.com/blog/smartphone. [Last accessed on 2013 May 23; Last accessed on 2014 Jan 21].

5. Lee YB. Positive and Negative Impact of Electronic Device on children. Hubpages network.; 2015. Available form: http://www.wehavekids. com.

6. In: Drotner $\mathrm{K}$, Livingstone $\mathrm{S}$, editors. International Handbook of Children, Media and Culture. London, UK: Sage Publications; 2008.

7. Valenzuela S, Park N, Kee KF. Is there social capital in a social network site? Facebook use and college students' life satisfaction, trust, and participation. J Comput Mediat Commun 2009;14:875-901.

8. Caplan SE. A social skill account of problematic internet use. J Commun 2005;55:721-36.

9. Kahn J, Moore KA. What Works for Home Visiting Programs: Lessons from Experimental Evaluations of Programs and Interventions; 2010. Available from: http://www.childtrends.org/?publications=what-works- 
for-home-visiting-programs-lessons-from-experimental-evaluations-ofprograms-and-interventions.

10. Hall CM, Bierman KL. Technology-assisted interventions for parents of young children: Emerging practices, current research, and future directions. Early Child Res Q 2015;33:21-32.
How to cite this article: George J, Mistry M. A Study to Assess the Effectiveness of Video-assisted Teaching on the Knowledge of Parents Regarding the Effects of Smartphone Overuse on the Growth and Development of Pre-schoolers in Selected Schools of Navi Mumbai. Int J Nurs Med Invest. 2019;4(2):31-35. 